Review Article

\title{
The Needs of Current Implant Technology in Orthopaedic Prosthesis Biomaterials Application to Reduce Prosthesis Failure Rate
}

\author{
Ahmad Jabir Rahyussalim, ${ }^{1}$ Aldo Fransiskus Marsetio, ${ }^{1}$ Ifran Saleh, ${ }^{1}$ \\ Tri Kurniawati, ${ }^{2}$ and Yudan Whulanza ${ }^{3}$ \\ ${ }^{1}$ Department of Orthopaedics and Traumatology, Faculty of Medicine, Universitas Indonesia, \\ Dr. Cipto Mangunkusumo General Hospital, Jakarta 10320, Indonesia \\ ${ }^{2}$ Stem Cell and Tissue Engineering Cluster, MERC Faculty of Medicine, University of Indonesia, \\ Dr. Cipto Mangunkusumo Hospital, Jakarta, Indonesia \\ ${ }^{3}$ Department of Metallurgy and Material, Faculty of Engineering, Universitas Indonesia, Depok, Jawa Barat 16424, Indonesia
}

Correspondence should be addressed to Ahmad Jabir Rahyussalim; rahyussalim71@ui.ac.id

Received 22 June 2016; Revised 22 September 2016; Accepted 17 October 2016

Academic Editor: Mohammad A. Islam

Copyright (c) 2016 Ahmad Jabir Rahyussalim et al. This is an open access article distributed under the Creative Commons Attribution License, which permits unrestricted use, distribution, and reproduction in any medium, provided the original work is properly cited.

\begin{abstract}
Today, orthopaedics is still in search for the most reliable biomaterial for prosthesis. The biomaterial needs to have good longevity and other supporting properties in order to maintain low implant failure. An ideal metallic biomaterial should be biocompatible, has similar elastic modulus to that of bone, has excellent resistance to fatigue, corrosion, aseptic loosening, and wear, and has good bone-bonding ability. The success of an implant depends on many factors. Good osseointegration is one of the factors required to reduce the rate of loosening of implants and in order to increase the chance of osseointegration, high stability of implants and early healing process encouragement are needed.
\end{abstract}

\section{Introduction}

Mobility is one of human basic needs. Although accidents can be prevented, one cannot avoid growing old. Degenerative and inflammatory diseases of the bones and joints are some common orthopaedic problems. These conditions are often found as chronic diseases in elderlies. In the midst of healthcare improvement, aging population keeps increasing and dominating the world's population. It is predicted that the number of people over 50 years of age who have bone diseases will be doubled by 2020 [1]. Most of these conditions require surgery, for example, internal fixation or total joint replacement. These kinds of surgeries will need device(s) to be implanted inside the body and biomaterials are adopted in orthopaedic application as the constituent of such devices.

By definition, biomaterials are substances that are engineered to be biocompatible materials used to replace or assist part of an organ or tissue while in intimate contact with the body and body fluids $[1,2]$. Biomaterials will be used as the constituent of device(s) that are intended to treat abnormal anatomical parts of human body, either by improving or substituting the bones, cartilages, ligaments, or tendons. Biological materials, such as bone allografts, are also considered to be biomaterials. In orthopaedics, these devices are commonly known as implants or prostheses. Currently, there is still a great need to find novel and improved biomaterials that are able to perform correctly with good compatibility and satisfactory longevity.

Biocompatibility, no foreign body reaction, appropriate design, good manufacturability of implants, biomechanical stabilities (stress shielding), good biomaterial properties, and resistance to implant wear, aseptic loosening, corrosion resistance, bioactivity, and osteoconduction are the main fundamental requirements for an implantable orthopaedic device $[1,3]$. The biomaterial properties must be aptly studied and analyzed in regard to tensile strength, yield strength, 
elastic modulus, corrosion and fatigue resistance, surface finish, creep, and hardness. If these requirements are not fulfilled, they will provoke failure process.

Human body is a highly corrosive environment. On the other hand, biomaterials are able to release ions and particles after implantation. Both will interact when they come into contact, and, therefore, there are many requirements for a biomaterial to be able to be implanted inside a human body. Biocompatibility refers to the interaction or responses of host cells and tissues with the implanted biomaterial. Additionally, biocompatibility also means that the design of the medical device has good biological safety while performing useful functions. According to IUPAC recommendations (2012), biocompatibility is the ability of a material to be in contact with living systems without producing an adverse effect [10]. It is then further classified according to the ability or tendency to produce cytotoxicity, carcinogenicity, mutagenicity, pyrogenicity, and allergenicity or thrombogenicity. Material of a metallic implant should be made of nontoxic elements and causing no inflammatory or allergic reactions to human body.

The following review will explore the fundamental requirements of metallic biomaterials to be used as orthopaedic implants. Conclusions will be drawn from this review regarding to the needs in studying novel biomaterials in order to improve the properties and endurance of the biomaterials being used as implants.

\section{Osseointegration}

The major causes of implant loosening are the inability of the implant surface to merge with the adjacent bone tissue [2]. Osseointegration is defined by Brånemark as "the direct structural and functional connections between the ordered, living bone and the surface of a load-carrying implant" [11]. Brånemark observed this phenomenon when he found that chambers made of metal titanium could form stable fixation with bone tissue. In modern day, Guo et al. define osseointegration as "the formation of a direct structural and functional connections between the implant and the surrounding bone tissue without any intervening connective tissue" [12]. They observed this integration based on the histological view.

After an implant is inserted into the bone, inflammatory reaction, which is followed by hematoma, will occur. Subsequently, a cascade of complex reactions will develop together from the bone side and from the implant side. From the bone side, there will be a platelet activation, followed by migration and activation of inflammatory cells. Revascularization will occur; mesenchymal cells and osteoblast will proliferate and adhere to the new bone-material interface. Protein synthesis and local factor composition will further support the integration process. From the implant side, the metallic biomaterials will undergo oxidation. Osteoblast will attach and osteogenic cells will deposit on the implant surface. Following the process, the osteoblast will deposit collagen matrix. This collagen matrix will form woven bone formation, which subsequently will transform into lamellar bone. The process could progress either from the bone to the implant surface (by means of distance osteogenesis) or from the implant to the healing bone (by means of contact osteogenesis or new bone formation) [13].

There are some factors determining osseointegration. Design, chemical composition, surface topography, and coating of the implant may add the chance of osseointegration. On the contrary, inappropriate porosity of the materials may hinder osseointegration. Minimal surgical trauma towards the bone bed and good vascularity and cellularity of implantation site may support the integration process. However, factors such as bone defect, osteoporosis, rheumatoid arthritis, smoking, and advanced age may inhibit the process. Primary mechanical stability of the implant is another factor that determines good osseointegration. At the same time, adjuvant therapies such as bone grafting (either autogenous or allograft), osteogenic coatings (such as BMPs, TGF- $\beta$ ), biophysical stimulation, and systemic administration of ibandronate and human parathyroid hormone may enhance the process. However, irradiation and pharmacological agents, such as cisplatin, warfarin, indomethacin, cyclosporine, and methotrexate, are found to inhibit the osseointegration process [13].

Among all metals, titanium alloy (Ti-6Al-4V) has more close relation with bone tissue as shown by Anselme et al. This is due to a stable oxide layer $\left(\mathrm{TiO}_{2}\right)$ formed on the titanium surface which prevents corrosion. However, these types of implants still can loose as they need further modifications. Some studies tried to modify the alloy to increase osseointegration, for example, by increasing the surface roughness [14-16], adding $\mathrm{NH}_{2}$ and $\mathrm{OH}$ functional groups on the surface $[17,18]$, increasing wettability and adding hydrophilic surface $[19,20]$, adding coatings such as calcium phosphate or hydroxyapatite [21-23], integrin manipulation [24-28], coating with growth factors [29-34], or coating with bisphosphonate [35-38].

An implant can be regarded as osseointegrated when the implant and the adhered bone show no progressive relative movement during physiological load bearing condition [39]. Good osseointegration is determined by surface chemistry, surface roughness, and surface topography [2]. Additionally, the minimal distance between the implant and the bone should be no more than $1 \mathrm{~mm}$ [40]. Poor osseointegration is often found in implants with low stability, young active patients, osteoporosis patients, and patients with delayed healing process.

\section{Nanostructure Interface}

The content of our bone nanostructure can be divided into organic and inorganic content. Type 1 collagen comprises $35 \%$ of the organic content of the bone nanostructure. Hydroxyapatite $\left(\mathrm{Ca}_{10}(\mathrm{PO} 4)_{6}(\mathrm{OH})_{2}\right)$ dominates the inorganic content, and the remainder is the ion substituted forms $[4,5$, 41]. This formation is also known as collagen-hydroxyapatite crystal arrangement of the bones (Figure 1). Type 1 collagen has a characteristic length of $300 \mathrm{~nm}$ and diameter of $1.5 \mathrm{~nm}$. The fibers are aligned parallel to each other but spread out to form collagen fibrils. The accumulation of fibrils will form collagen bands, which appear as alternating dark and light shade in electron microscope with periodicity 


\section{Collagen fibril arrangement Longitudinal view}

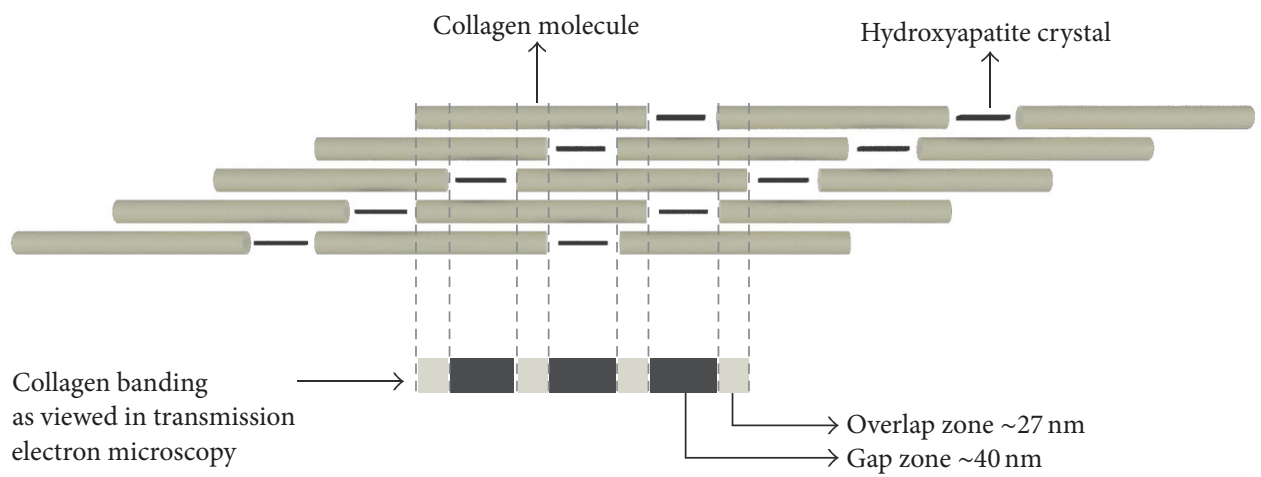

(a)

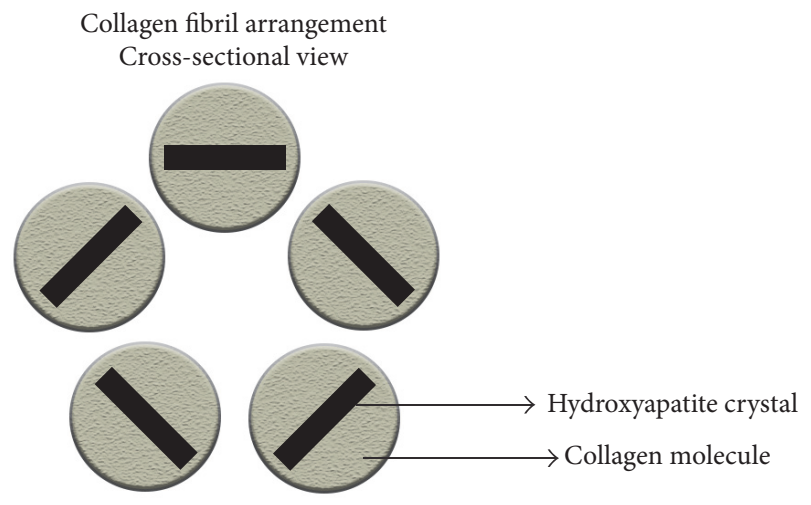

(b)
Collagen fibril arrangement Diagonal three-dimensional view

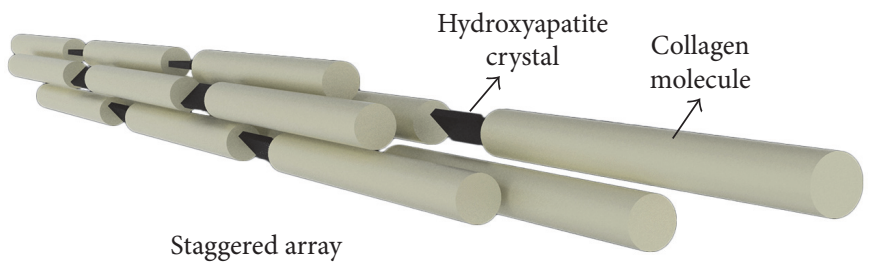

(c)

FIGURE 1: Nanostructure of the bone: the collagen-hydroxyapatite crystal arrangement in bone. The staggered array resulting in alternating light and dark bands in transmission electron microscope called collagen banding [4]. (a) Longitudinal view; (b) cross-sectional view; (c) diagonal three-dimensional view. Adapted from [4].

of $67 \mathrm{~nm}$ (Figure 2). Inorganic components will appear in the form of plate-like fibers with a characteristic length of 50-100 nm, width of 25-50 nm, and thickness of 4-6 nm. They are predominantly located in the gap zone and contain intermolecular and extrafibrillar apatite. All of these collagen fibrils will bind to each other to form collagen fibers and form, ultimately, cortical and trabecular bone structures.

In order to fulfill the safety requirements and being implanted for a long time with no rejection reaction, metallic implants to be used as bone prostheses should have the following properties: nontoxic, excellent biocompatibility, high resistance towards corrosion, good mechanical properties as intended, high resistance to wear, and good osseointegration [2]. When synthetic metal biomaterials are implanted inside the human body, they will elicit various host responses. Based on the interaction with the body, synthetic materials may be classified into nearly inert, bioactive, and resorbable [42]. Nearly inert materials will elicit only minimal reaction to the body. Some examples of nearly inert materials are stainless steel, alumina, zirconia, and polyethylene. Bioactive materials will form biologically active layer upon implantation. Such materials include hydroxyapatite, glass ceramic A-W, and bioglass. Resorbable materials, on the other hand, will eventually be replaced by natural tissue over time. The examples of these materials are tricalcium phosphate and polylacticpolyglycolic polymers.

There are also some factors affecting the biological response of the biomaterials. The factors include chemical composition, crystallinity, surface topography, pore size, morphology, and connectivity [42].

\section{Corrosion Endurance}

The most probable biocompatible materials may be selected from alloy elements that already exist naturally in the human body [2]. Human body needs many metal trace elements or metal micronutrients. However, these elements are toxic at the levels higher than they are required. In reality, there are no materials that are completely inert or nontoxic to human body over a prolonged period of use. Therefore, alloys composed of practically inert elements or elements that are existed as trace elements in human body could be used in constructing metallic implants. Otherwise, highly corrosionresistant elements, such as titanium, should be used. 


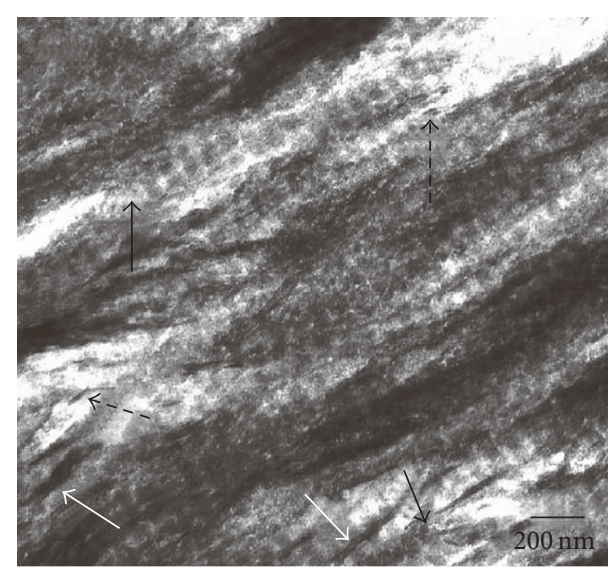

(a)

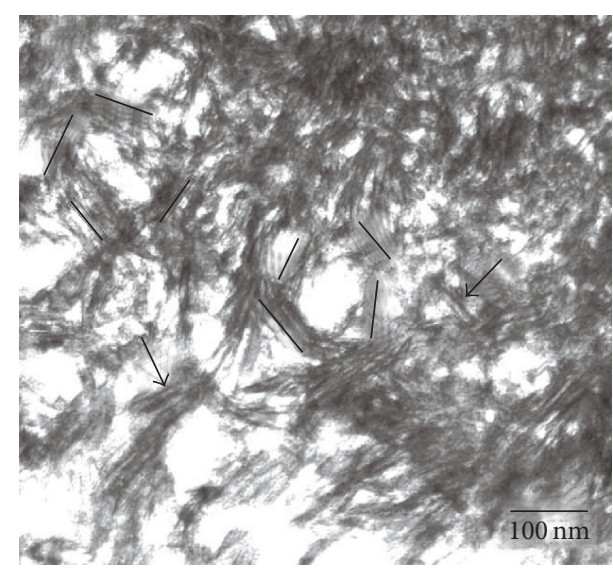

(b)

FIgURE 2: Nanostructure of the bone, as viewed by electron microscope [5]. Taken from [5].

As mentioned before, the highly corrosive environment inside the human body may cause metals with good performance at room conditions to suffer severe corrosion inside the human body [2]. In fact, stainless steel, the most corrosion-resistant metal, will cause chronic allergy and toxic reactions after a prolonged implantation period. There are four types of corrosion observed upon metallic biomaterial exposure to biological fluids. When the metal is immersed in the body fluid, two different areas of the same metal surface could have different electrochemical potential resulting in corrosion known as galvanic corrosion. In pitting corrosion, the different potential is localized, causing localized depassivation of the surface, hence forming pits. Similarly, crevice corrosion also occurs in confined space with low oxygen tension, low $\mathrm{pH}$, and high chloride concentration leading to the destruction of the passivation layer. Crevice corrosion is more likely to occur at the attachment site of metal parts. Fretting corrosion occurs due to deterioration of the passivation layer at the interface between two contacting layers as a result of micromotion. The corrosion occurs at the weight bearing surfaces.

Different parts and different condition of the body have different $\mathrm{pH}$ values and oxygen concentrations. Although usually body fluids have nearly neutral $\mathrm{pH}$ value (7.2-7.4 at $37^{\circ} \mathrm{C}, 1 \mathrm{~atm}$ ), this value may drop to $3-4$ in case of inflammation [43]. This $\mathrm{pH}$ change could be influenced by inflammatory cells generated by trauma or surgery. The internal partial pressure of oxygen inside the body is about one-quarter of the atmospheric oxygen pressure. Although low oxygen means less oxidation, the deceleration of protective passive oxide films formation on metal surface actually accelerates corrosion process.

Metal ions, metallic compounds, and debris will be released in conjunction with wear process. These corrosion particles will induce local toxicity and foreign body reactions when they come into contact with surrounding tissues $[44,45]$. If the debris is soluble, it will go with the blood flow and be secreted via urine. However, if the debris is insoluble, the particles will accumulate in the tissues/lymph nodes/bone marrow. The short term effects of debris accumulation are inflammation and cell tissue damage [44]. The long term effects are hypersensitivity, chromosomal aberrations, and toxicity/carcinogenicity. In long term, macrophages will engulf the particles as foreign bodies. However, these macrophages tend to be killed by the foreign particles after ingestion. Enzymes and metabolites released by the dying macrophages will change the surrounding microenvironment to acidic. Large amount of debris could be released by the dying macrophages leading to a phenomenon known as metallosis [2]. These enzymes, acidic chemicals, and ions and debris contribute to aseptic loosening of the implant.

\section{Mechanical Properties}

As an orthopaedic implant, biomaterial has the task to replace the basic mechanical functions of the bone. The basic mechanical functions of the bone include supporting, protecting, and aiding body movements. Therefore, the structure of the biomaterial should be strong and tough. Young's modulus, ultimate tensile strength (UTS), and toughness are the important mechanical properties of the biomaterials developed [2].

Young's modulus is a mechanical property showing the ratio of the stress and the strain of a linear elastic solid material (Figure 3). The higher the modulus, the greater the mechanical load that can be borne by the structure. Young's modulus of human bone is $10-30 \mathrm{GPa}$ [46]. Unfortunately, the biomaterials that currently are available have a much higher GPa (more than $100 \mathrm{GPa}$ ). Young's modulus of stainless steel is $200 \mathrm{GPa}$, titanium alloy is $110 \mathrm{GPa}$, cobalt chromium is $220-230 \mathrm{GPa}$, and tantalum is $200 \mathrm{GPa}$. This may cause what is called as stress shielding effect. The effect occurs due to the high mechanical load borne by the implant, while the bone surrounding the implant bears less mechanical load. In the future, the bone will undergo atrophy and requires further revision surgery.

During walking, the mechanical load changes dynamically [2]. During a step, there is a time when the whole human body is only supported by a single leg. This walking cycle, 


$$
\begin{aligned}
& \text { Young's modulus } \\
& E=\frac{\text { Stress }}{\text { Strain }}=\frac{F / A}{\Delta L / L}
\end{aligned}
$$

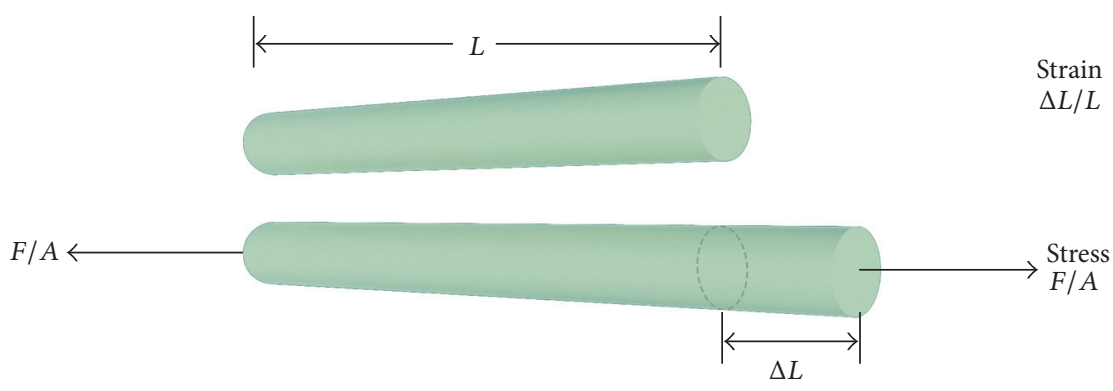

FIGURE 3: Young's modulus concept of stress and strain of linear elastic solid materials.

or the stress cycle, occurs many times a day, up to 730,000 per year. The maximum number of stress cycle that can be applied to a material without causing failure is called fatigue strength or endurance limit. When a material is subjected to its endurance limit, it may break even with a normal amount of stress, without any prior warning signs. Combined with cyclic friction, and if the friction stress superimposed with plain fatigue stress, it will come into a condition that is known as fretting fatigue.

About ten years ago, the ten-year failure rate of hip replacement was $26 \%$ [47]. While the ten-year failure rate of knee replacement could be up to $14 \%$ [48]. However, with the advancement of technology, the longevity of hip and knee replacement today can be up to more than $90 \%$ in 15 years $[49,50]$. However, this lifespan is usually decreased in young active patients or patients with decreased bone quality or osteoporotic. The most common causes of revision in total hip replacement are aseptic loosening (55.2\%), dislocation $(11.8 \%)$, septic loosening $(7.5 \%)$, periprosthetic fractures (6\%), and others [47]. In order to increase the chance of osseointegration, high stability of implants and early healing process encouragement are needed. Delayed healing process may result in the development of fibrous tissue. Micromotion will lead to fibrous tissue formation around the implant. One study by Bacakova et al., examined the effect of oscillating micromotion on osseointegration in implant in dog distal femurs [51]. They found that bone ingrowth was not supported when the structure received 40 and $150 \mu \mathrm{m}$ of micromotion. However, osseointegration ability was not disrupted when the micromotion was only $20 \mu \mathrm{m}$.

\section{Biomaterial Surface}

Surface energy relates to hydrophilic properties of a material. It can be defined as an excess of free energy per unit area and can be measured by the contact angles made by water droplets. Surface with high contact angles can be considered as hydrophobic, while low contact angles can be considered as hydrophilic. This is also called wettability. Surface energy increases concomitantly with the increase in roughness of metallic surface. Additionally, surface energy also increases proportionally with the increase in propensity and strength of cellular adhesion to metallic surface [52].

Although cell proliferation is found to be impaired, surface with high wettability (hydrophilic) is able to increase the induction of osteoblast differentiation and the release of local growth factors $[53,54]$. It has been shown that higher wettability of an implant surface will result in better bone apposition and bone implant contact [55]. Adsorption of matrix proteins, such as fibronectin and collagen, plays important roles in increasing cell adhesion [52].

One example of material with good wettability is titanium. When an implant with titanium-based biomaterial is implanted, it forms a hydrophilic $\mathrm{TiO}_{2}$ layer. This layer modifies the strength of the cell surface integrins binding to fibronectin-coated surfaces, in vitro [17]. It adsorbs matrix protein and reorganizes the adhering cells, hence improving the adhesion and the spread of the cells [56].

In addition to increase the wettability and the roughness, further modification also attempts to increase the surface energy. This includes the use of UV light to render the hydrophobic surface superhydrophilic. This process, which is also called photofunctionalization, will enhance further the adsorption of protein, proliferation, and differentiation of osteoblast, attachment of osteoblast, in vitro proliferation and phenotype expression, and in vivo fixation of implant [56]. Another method of surface modification in order to enhance the osteoblast adhesion to implant surface is by topographical modification. Surface orientation and roughness define the surface topography, while series of peaks and valleys give the surface topography a characteristic. This modification acts as the surface guidance for the cells to adhere. The modification can be additive (coating) or subtractive (etching). The end result of this modification is increased surface area and alteration of the surface's chemical composition and energy [57].

The greater the surface microtopography, the larger the surface area for fibrinogen adsorption, which will lead to enhanced platelet adhesion and activation. In an in vitro study, it is shown that this could elicit osteogenic reactions 
TABLE 1: Some metallic biomaterials that are currently used or being studied for orthopaedic implants.

\begin{tabular}{|c|c|c|c|c|c|c|}
\hline Materials & $\begin{array}{l}\text { Elastic } \\
\text { modulus } \\
(\mathrm{GPa})\end{array}$ & $\begin{array}{l}\text { Yield } \\
\text { strength } \\
(\mathrm{MPa})\end{array}$ & $\begin{array}{c}\text { Ultimate } \\
\text { strength }(\mathrm{MPa})\end{array}$ & Corrosive resistance & Advantages & Drawbacks \\
\hline Stainless steel [6] & 200 & $215 \mathrm{MPa}$ & $505 \mathrm{MPa}$ & $\begin{array}{l}\text { Corrosive resistance } \\
\text { due to high } \mathrm{Cr} \\
\text { content }\end{array}$ & $\begin{array}{l}\text { Formation of a film of } \\
\text { chromium oxide on } \\
\text { the surface of the steel } \\
\text { at a molecular level, } \\
\text { which is passive, } \\
\text { adhesive, tenacious, } \\
\text { and self-healing }\end{array}$ & $\begin{array}{l}\text { Large amount of wear } \\
\text { debris, poor wear } \\
\text { resistance, worse } \\
\text { corrosion resistance, } \\
\text { and dangerous } \\
\text { allergic reaction } \\
\text { appears in a high } \\
\text { number of patients }\end{array}$ \\
\hline $\begin{array}{l}\text { Titanium and } \\
\text { titanium alloy } \\
(\text { Ti-6Al-4V) }[6,7]\end{array}$ & $110-119$ & $850-900$ & $960-970$ & $\begin{array}{l}\text { Stable oxide layer } \\
\left(\text { Titania- } \mathrm{TiO}_{2}\right) \text { on the } \\
\text { titanium surface } \\
\text { ( } 2 \mathrm{~nm} \text { thick) }\end{array}$ & $\begin{array}{l}\text { High mechanical } \\
\text { strength, superior } \\
\text { biocompatibility, } \\
\text { corrosion and wear } \\
\text { resistance, rapid } \\
\text { osseointegration, } \\
\text { enhanced osteoblast } \\
\text { adhesion, and } \\
\text { complete inertness to } \\
\text { body environment }\end{array}$ & $\begin{array}{l}\text { Potential toxicity to } \\
\text { vanadium }\end{array}$ \\
\hline $\begin{array}{l}\text { Cobalt-chrome } \\
\text { (Co-Cr-Mo) alloys } \\
{[6]}\end{array}$ & $220-230$ & $275-1585$ & $600-1785$ & $\begin{array}{l}\text { Excellent, even in } \mathrm{Cl}^{-} \\
\text {environments }\end{array}$ & $\begin{array}{l}\text { Highly resistant to } \\
\text { corrosion even in } \\
\text { chloride environment } \\
\text { due to spontaneous } \\
\text { formation of passive } \\
\text { oxide layer within the } \\
\text { human body } \\
\text { environment }\end{array}$ & $\begin{array}{l}\text { The corrosion } \\
\text { products of } \\
\text { Co-Cr-Mo are more } \\
\text { toxic than those of } \\
\text { stainless steel } 316 \mathrm{~L} \\
(\mathrm{Ni}, \mathrm{Cr} \text {, and } \mathrm{Co})\end{array}$ \\
\hline $\begin{array}{l}\text { Unalloyed } \\
\text { tantalum }[8,9]\end{array}$ & 186 & $138-345$ & $207-517$ & $\begin{array}{l}\text { Highly corrosive } \\
\text { resistance }\end{array}$ & $\begin{array}{l}\text { High yield and } \\
\text { ultimate strength, } \\
\text { good bone-bonding }\end{array}$ & $\begin{array}{l}\text { Long term data not } \\
\text { yet available }\end{array}$ \\
\hline $\begin{array}{l}\text { Porous tantalum } \\
{[8,9]}\end{array}$ & $2.5-3.9$ & $35-51$ & $50-110$ & $\begin{array}{l}\text { Highly corrosive } \\
\text { resistance }\end{array}$ & $\begin{array}{l}\text { Young's modulus } \\
\text { similar to } \\
\text { subchondral bone } \\
\text { with ten times yield } \\
\text { and ultimate strength, } \\
\text { usually used as } \\
\text { coating of trabecular } \\
\text { metal, good } \\
\text { biocompatibility of } \\
\text { tantalum, and } \\
\text { titanium }\end{array}$ & $\begin{array}{l}\text { Long term data not } \\
\text { yet available }\end{array}$ \\
\hline
\end{tabular}

[52]. The more complex the implant surface, the more preferable the environment for fibrin attachment, thus establishing a temporary osteoconductive matrix [58]. These associations among the surface texture, osteoconductive matrix formation, and subsequent recruitment of osteogenic cells will influence the process of contact osteogenesis, new bone formation, and implant integration.

In addition to the roughness of surface, material porosity is also one of the factors that influence the interaction between bone and materials. Study found that bony ingrowth within the material requires a pore size between 50 and $400 \mu \mathrm{m}$. This porous structure is also essential for supporting the vascular formation, proliferation of mesenchymal cells, and osteogenesis within the material. However, if the pore size is greater than $1 \mathrm{~mm}$, fibrotic tissue ingrowth is more likely to occur [59].

\section{Available Metallic Biomaterials}

There are several metallic biomaterials that have already been used as orthopaedic implants. The characteristics of some of them, including the elastic modulus, yield strength, ultimate strength, corrosive resistance, advantage(s), and drawback(s), are summarized in Table 1 . Some studies of biomaterial surface modifications in achieving osseointegration are aiming not only at biocompatibility but also at bioactivity. The process of rendering the material to be more bioactive is also called biofunctionalization [60]. 
Among the coatings for biometallic surfaces that have been implemented and studied, hydroxyapatite is among the first studies. Hydroxyapatite provides bioactive materials with osteoconductivity by forming precipitated apatite layer, and studies showed that it would double the strength of mechanical fixation in 4 weeks in vivo compared to uncoated Ti. Another osteoconductive coating is calcium phosphate, which has bioactive interaction through protein adsorption. Coating with fluoride is also found to increase the number of attached cells, induce osteoblast differentiation, increase mineral density at the interface, and improve pullout force by altering the surface chemistry and nanotopography. One study also found that Strontium (Sr) coating is able to enhance attachment, spreading, and differentiation of osteoblast [61].

Oral bisphosphonate supplement is also found able to significantly enhance early new bone formation at the interface and inhibit peri-implant bone resorption. However, in long term use it increases the risk of atypical fractures. Local application of factors may increase bone remodeling; for example, VEGF may enhance bone mineralization, collagen may improve osseointegration (by increasing differentiation and adhesion of osteoblast), and RGD-sequence-containing peptide may accelerate tissue integration (by promoting osteoblast attachment, differentiation, production, and osteoclast differentiation) [61]. Constant delivery of Bone Morphogenetic Protein (BMP) in moderate dose was found to stimulate osteoblast differentiation; however if it is given too much, it may impair the osteoconductivity drastically [62]. Local antibiotics may be given to prevent septic loosening. Other coatings being studied may include other organic agents, bioactive molecules, and cytokines/chemokines [61].

Recently, there is a new biomaterial being studied as the main material for orthopaedic implant. The material is Ti-24Nb-4Zr-7.9Sn (TNZS), developed by the Institute of Metal Research Chinese Academy of Science [63]. The novel material has low elastic modulus $(42 \mathrm{GPa}$ ) but possesses high strength (800-900 MPa). Its surface roughness is similar to titanium alloy. Study found significantly higher ALP activity seven days after implantation, with higher pullout strength at 12 weeks. Micro-CT analysis showed greater bone formation at 12 weeks, with direct bone-to-implant contact, disappearance of fibrous tissue and osteoid, and replacement by new bone tissue.

\section{Summary and Remarks}

Technological advancement of biomaterial manufacturing and research have driven the development of main biomaterials and coating for orthopaedic implants. An ideal metallic biomaterial should be biocompatible and should possess elastic modulus properties as close as those of bone, high strength, excellent resistance to fatigue, corrosion, aseptic loosening and wear, and good bone-bonding ability. Although titanium is imperfect, it is still being the dominant material used in orthopaedic implants. Research findings regarding porous metallic implant with modified surface or coating with Young's modulus close to the bones are needed in order to improve the current implant technology.
Researches are needed to find biomaterials that can withstand daily load and improve the long term success of the metallic implant.

\section{Competing Interests}

The authors have no financial competing interests.

\section{References}

[1] M. Navarro, A. Michiardi, O. Castaño, and J. A. Planell, "Biomaterials in orthopaedics," Journal of the Royal Society Interface, vol. 5, no. 27, pp. 1137-1158, 2008.

[2] Q. Chen and G. A. Thouas, "Metallic implant biomaterials," Materials Science and Engineering R: Reports, vol. 87, pp. 1-57, 2015.

[3] F. Rodríguez-González, Biomaterials in Orthopaedic Surgery, ASM International, Materials Park, Ohio, USA, 2009.

[4] K. Grandfield, Nanoscale Osseointegration: Characterization of Biomaterials and their Interfaces with Electron Tomography, Acta Universitatis Upsaliensis: Uppsala Universitet, 2012.

[5] M. A. Rubin, I. Jasiuk, J. Taylor, J. Rubin, T. Ganey, and R. P. Apkarian, "TEM analysis of the nanostructure of normal and osteoporotic human trabecular bone," Bone, vol. 33, no. 3, pp. 270-282, 2003.

[6] T. Jinno, V. M. Goldberg, D. Davy, and S. Stevenson, "Osseointegration of surface-blasted implants made of titanium alloy and cobalt-chromium alloy in a rabbit intramedullary model," Journal of Biomedical Materials Research, vol. 42, no. 1, pp. 2029, 1998.

[7] B. Levine, C. J. Della Valle, and J. J. Jacobs, "Applications of porous tantalum in total hip arthroplasty," The Journal of the American Academy of Orthopaedic Surgeons, vol. 14, no. 12, pp. 646-655, 2006.

[8] B. R. Levine, S. Sporer, R. A. Poggie, C. J. Della Valle, and J. J. Jacobs, "Experimental and clinical performance of porous tantalum in orthopedic surgery," Biomaterials, vol. 27, no. 27, pp. 4671-4681, 2006.

[9] Y. Liu, L. Enggist, A. F. Kuffer, D. Buser, and E. B. Hunziker, "The influence of BMP-2 and its mode of delivery on the osteoconductivity of implant surfaces during the early phase of osseointegration," Biomaterials, vol. 28, no. 16, pp. 2677-2686, 2007.

[10] P.-I. Branemark, "Osseointegration and its experimental background," The Journal of Prosthetic Dentistry, vol. 50, no. 3, pp. 399-410, 1983.

[11] C. Y. Guo, J. P. Matinlinna, and A. T. H. Tang, "Effects of surface charges on dental implants: past, present, and future," International Journal of Biomaterials, vol. 2012, Article ID 381535, 5 pages, 2012.

[12] R. Dimitriou and G. C. Babis, "Biomaterial osseointegration enhancement with biophysical stimulation," Journal of Musculoskeletal \& Neuronal Interactions, vol. 7, no. 3, pp. 253-265, 2007.

[13] A. B. Novaes Jr., S. L. S. de Souza, R. R. M. de Barros, K. K. Y. Pereira, G. Iezzi, and A. Piattelli, "Influence of implant surfaces on osseointegration," Brazilian Dental Journal, vol. 21, no. 6, pp. 471-481, 2010

[14] K. Anselme and M. Bigerelle, "Topography effects of pure titanium substrates on human osteoblast long-term adhesion," Acta Biomaterialia, vol. 1, no. 2, pp. 211-222, 2005. 
[15] M. M. Shalabi, A. Gortemaker, M. A. Van't Hof, J. A. Jansen, and N. H. J. Creugers, "Implant surface roughness and bone healing: a systematic review," Journal of Dental Research, vol. 85, no. 6, pp. 496-500, 2006.

[16] B. G. Keselowsky, D. M. Collard, and A. J. García, "Surface chemistry modulates fibronectin conformation and directs integrin binding and specificity to control cell adhesion," Journal of Biomedical Materials Research-Part A, vol. 66, no. 2, pp. 247-259, 2003.

[17] B. G. Keselowsky, D. M. Collard, and A. J. García, "Integrin binding specificity regulates biomaterial surface chemistry effects on cell differentiation," Proceedings of the National Academy of Sciences of the United States of America, vol. 102, no. 17, pp. 5953-5957, 2005.

[18] F. Rupp, L. Scheideier, N. Olshanska, M. De Wild, M. Wieland, and J. Geis-Gerstorfer, "Enhancing surface free energy and hydrophilicity through chemical modification of microstructured titanium implant surfaces," Journal of Biomedical Materials Research-Part A, vol. 76, no. 2, pp. 323-334, 2006.

[19] Y.-T. Sul, C. B. Johansson, Y. Jeong, A. Wennerberg, and T. Albrektsson, "Resonance frequency and removal torque analysis of implants with turned and anodized surface oxides," Clinical Oral Implants Research, vol. 13, no. 3, pp. 252-259, 2002.

[20] K. Soballe, "Hydroxyapatite ceramic coating for bone implant fixation. Mechanical and histological studies in dogs," Acta Orthopaedica Scandinavica Supplementum, vol. 255, pp. 1-58, 1993.

[21] F. Barrère, C. M. Van Der Valk, G. Meijer, R. A. J. Dalmeijer, K. De Groot, and P. Layrolle, "Osteointegration of biomimetic apatite coating applied onto dense and porous metal implants in femurs of goats," Journal of Biomedical Materials Research-Part B Applied Biomaterials, vol. 67, no. 1, pp. 655-665, 2003.

[22] S. D. Cook, K. A. Thomas, J. E. Dalton, T. K. Volkman, T. S. Whitecloud III, and J. F. Kay, "Hydroxylapatite coating of porous implants improves bone ingrowth and interface attachment strength," Journal of Biomedical Materials Research, vol. 26, no. 8, pp. 989-1001, 1992.

[23] T. A. Petrie, J. E. Raynor, D. W. Dumbauld et al., "Tissue engineering: multivalent integrin-specific ligands enhance tissue healing and biomaterial integration," Science Translational Medicine, vol. 2, no. 45, article 45ra60, 2010.

[24] A. J. García, "Get a grip: integrins in cell-biomaterial interactions," Biomaterials, vol. 26, no. 36, pp. 7525-7529, 2005.

[25] T. A. Barber, J. E. Ho, A. De Ranieri, A. S. Virdi, D. R. Sumner, and K. E. Healy, "Peri-implant bone formation and implant integration strength of peptide-modified $\mathrm{p}$ (AAm-co-EG/AAc) interpenetrating polymer network-coated titanium implants," Journal of Biomedical Materials Research Part A, vol. 80, no. 2, pp. 306-320, 2007.

[26] C. D. Reyes, T. A. Petrie, K. L. Burns, Z. Schwartz, and A. J. García, "Biomolecular surface coating to enhance orthopaedic tissue healing and integration," Biomaterials, vol. 28, no. 21, pp. 3228-3235, 2007.

[27] T. A. Petrie, J. E. Raynor, C. D. Reyes, K. L. Burns, D. M. Collard, and A. J. García, "The effect of integrin-specific bioactive coatings on tissue healing and implant osseointegration," Biomaterials, vol. 29, no. 19, pp. 2849-2857, 2008.

[28] F. Thorey, H. Menzel, C. Lorenz, G. Gross, A. Hoffmann, and $\mathrm{H}$. Windhagen, "Osseointegration by bone morphogenetic protein- 2 and transforming growth factor beta 2 coated titanium implants in femora of New Zealand white rabbits," Indian Journal of Orthopaedics, vol. 45, no. 1, pp. 57-62, 2011.
[29] M. Ramazanoglu, R. Lutz, P. Rusche et al., "Bone response to biomimetic implants delivering BMP-2 and VEGF: an immunohistochemical study," Journal of Cranio-Maxillofacial Surgery, vol. 41, no. 8, pp. 826-835, 2013.

[30] K. Kashiwagi, T. Tsuji, and K. Shiba, "Directional BMP-2 for functionalization of titanium surfaces," Biomaterials, vol. 30, no. 6, pp. 1166-1175, 2009.

[31] K. Yuasa, E. Kokubu, K. Kokubun et al., "An artificial fusion protein between bone morphogenetic protein 2 and titaniumbinding peptide is functional in vivo," Journal of Biomedical Materials Research-Part A, vol. 102, no. 4, pp. 1180-1186, 2014.

[32] N. J. Shah, M. N. Hyder, J. S. Moskowitz et al., "Surface-mediated bone tissue morphogenesis from tunable nanolayered implant coatings," Science Translational Medicine, vol. 5, no. 191, Article ID 191ra83, 2013.

[33] Y. Lu, J. S. Lee, B. Nemke et al., "Coating with a modular bone morphogenetic peptide promotes healing of a bone-implant gap in an ovine model," PLoS ONE, vol. 7, no. 11, Article ID e50378, 2012.

[34] K. Wermelin, P. Aspenberg, P. Linderbäck, and P. Tengvall, "Bisphosphonate coating on titanium screws increases mechanical fixation in rat tibia after two weeks," Journal of Biomedical Materials Research-Part A, vol. 86, no. 1, pp. 220-227, 2008.

[35] K. Wermelin, F. Suska, P. Tengvall, P. Thomsen, and P. Aspenberg, "Stainless steel screws coated with bisphosphonates gave stronger fixation and more surrounding bone. Histomorphometry in rats," Bone, vol. 42, no. 2, pp. 365-371, 2008.

[36] T. Andersson, F. Agholme, P. Aspenberg, and P. Tengvall, "Surface immobilized zoledronate improves screw fixation in rat bone: a new method for the coating of metal implants," Journal of Materials Science: Materials in Medicine, vol. 21, no. 11, pp. 3029-3037, 2010.

[37] B. Skoglund, J. Holmertz, and P. Aspenberg, "Systemic and local ibandronate enhance screw fixation," Journal of Orthopaedic Research, vol. 22, no. 5, pp. 1108-1113, 2004.

[38] R. Brånemark, P.-I. Brånemark, B. Rydevik, and R. R. Myers, "Osseointegration in skeletal reconstruction and rehabilitation: a review," Journal of Rehabilitation Research and Development, vol. 38, no. 2, pp. 175-181, 2001.

[39] A. F. Mavrogenis, R. Dimitriou, J. Parvizi, and G. C. Babis, "Biology of implant osseointegration," Journal of Musculoskeletal \& Neuronal Interactions, vol. 9, no. 2, pp. 61-71, 2009.

[40] R. Z. LeGeros, "Properties of osteoconductive biomaterials: calcium phosphates," Clinical Orthopaedics and Related Research, no. 395, pp. 81-98, 2002.

[41] W. Cao and L. L. Hench, "Bioactive materials," Ceramics International, vol. 22, no. 6, pp. 493-507, 1996.

[42] M. Sumita and T. Hanawa, Failure Processes in Biometallic Materials, Elsevier Science, London, UK, 2003.

[43] M. Geetha, A. K. Singh, R. Asokamani, and A. K. Gogia, "Ti based biomaterials, the ultimate choice for orthopaedic implants-a review," Progress in Materials Science, vol. 54, no. 3, pp. 397-425, 2009.

[44] A. Yamamoto, T. Kobayashi, N. Maruyama, K. Nakazawa, and M. Sumita, "Fretting fatigue properties of Ti-6Al-4V alloy in pseudo-body fluid and evaluation of biocompatibility by cell culture method," Journal of the Japan Institute of Metals, vol. 59, no. 4, pp. 463-470, 1995.

[45] D. Bitar and J. Parvizi, "Biological response to prosthetic debris," World Journal of Orthopedics, vol. 6, no. 2, pp. 172-189, 2015. 
[46] S. A. Lie, L. I. Havelin, O. N. Furnes, L. B. Engesaeter, and S. E. Vollset, "Failure rates for 4762 revision total hip arthroplasties in the Norwegian Arthroplasty Register," The Journal of Bone and Joint Surgery -British Volume, vol. 86, no. 4, pp. 504-509, 2004.

[47] D. K. Bae, S. J. Song, D. B. Heo, S. H. Lee, and W. J. Song, "Long-term survival rate of implants and modes of failure after revision total knee arthroplasty by a single surgeon," The Journal of Arthroplasty, vol. 28, no. 7, pp. 1130-1134, 2013.

[48] X.-W. Liu, Y. Zi, L.-B. Xiang, and Y. Wang, "Total hip arthroplasty: a review of advances, advantages and limitations," International Journal of Clinical and Experimental Medicine, vol. 8, no. 1, pp. 27-36, 2015.

[49] Y. Abu-Amer, I. Darwech, and J. C. Clohisy, "Aseptic loosening of total joint replacements: mechanisms underlying osteolysis and potential therapies," Arthritis Research \& Therapy, vol. 9, no. 1, article S6, 2007.

[50] C. R. Bragdon, D. Burke, J. D. Lowenstein et al., "Differences in stiffness of the interface between a cementless porous implant and cancellous bone in vivo in dogs due to varying amounts of implant motion," The Journal of Arthroplasty, vol. 11, no. 8, pp. 945-951, 1996.

[51] L. Bacakova, E. Filova, M. Parizek, T. Ruml, and V. Svorcik, "Modulation of cell adhesion, proliferation and differentiation on materials designed for body implants," Biotechnology Advances, vol. 29, no. 6, pp. 739-767, 2011.

[52] G. Zhao, Z. Schwartz, M. Wieland et al., "High surface energy enhances cell response to titanium substrate microstructure," Journal of Biomedical Materials Research-Part A, vol. 74, no. 1, pp. 49-58, 2005.

[53] J. H. Park, C. E. Wasilewski, N. Almodovar et al., “The responses to surface wettability gradients induced by chitosan nanofilms on microtextured titanium mediated by specific integrin receptors," Biomaterials, vol. 33, no. 30, pp. 7386-7393, 2012.

[54] D. Buser, N. Broggini, M. Wieland et al., "Enhanced bone apposition to a chemically modified SLA titanium surface," Journal of Dental Research, vol. 83, no. 7, pp. 529-533, 2004.

[55] D. J. Iuliano, S. S. Saavedra, and G. A. Truskey, "Effect of the conformation and orientation of adsorbed fibronectin on endothelial cell spreading and the strength of adhesion," Journal of Biomedical Materials Research, vol. 27, no. 8, pp. 1103-1113, 1993.

[56] A. Wennerberg and T. Albrektsson, "Effects of titanium surface topography on bone integration: a systematic review," Clinical Oral Implants Research, vol. 20, no. 4, pp. 172-184, 2009.

[57] J. E. Davies, "Understanding peri-implant endosseous healing," Journal of Dental Education, vol. 67, no. 8, pp. 932-949, 2003.

[58] G. Ryan, A. Pandit, and D. P. Apatsidis, "Fabrication methods of porous metals for use in orthopaedic applications," Biomaterials, vol. 27, no. 13, pp. 2651-2670, 2006.

[59] R. Agarwal and A. J. García, "Biomaterial strategies for engineering implants for enhanced osseointegration and bone repair," Advanced Drug Delivery Reviews, vol. 94, pp. 53-62, 2015.

[60] V. Goriainov, R. Cook, J. M. Latham, D. G. Dunlop, and R. O. C. Oreffo, "Bone and metal: an orthopaedic perspective on osseointegration of metals," Acta Biomaterialia, vol. 10, no. 10, pp. 4043-4057, 2014.

[61] M. B. Nasab, M. R. Hassan, and B. B. Sahari, "Metallic biomaterials of knee and hip-a review," Trends in Biomaterials and Artificial Organs, vol. 24, no. 2, pp. 69-82, 2010.
[62] L. Shi, L. Shi, L. Wang et al., "The improved biological performance of a novel low elastic modulus implant," PLOS ONE, vol. 8, no. 2, article e55015, 2013.

[63] Y. L. Hao, S. J. Li, S. Y. Sun, C. Y. Zheng, Q. M. Hu, and R. Yang, "Super-elastic titanium alloy with unstable plastic deformation," Applied Physics Letters, vol. 87, no. 9, Article ID 091906, 2005. 

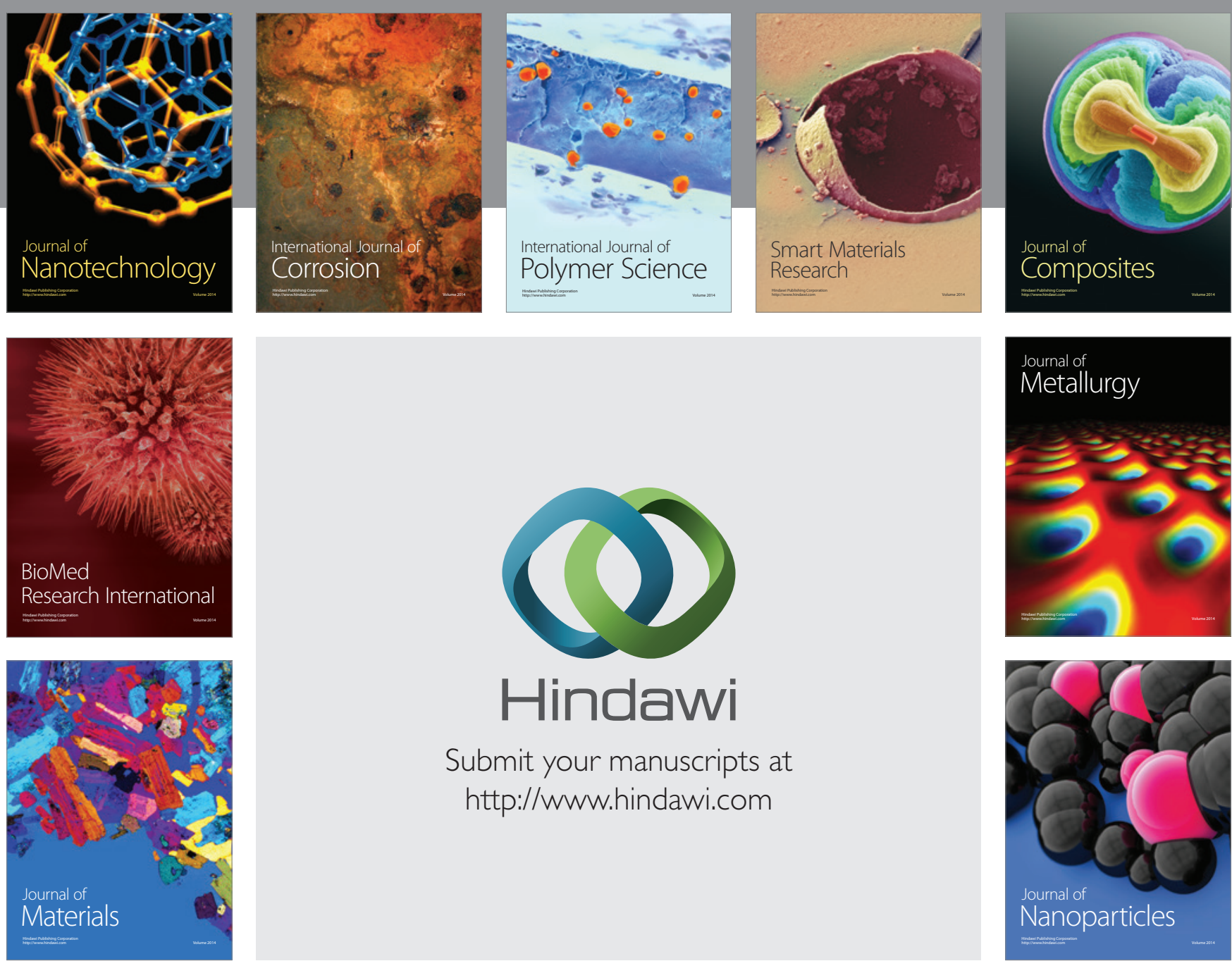

\section{Hindawi}

Submit your manuscripts at

http://www.hindawi.com

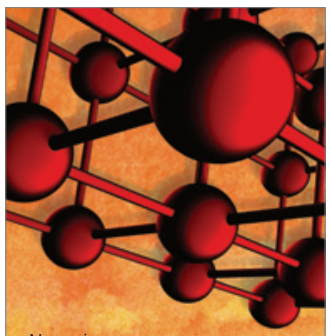

Materials Science and Engineering
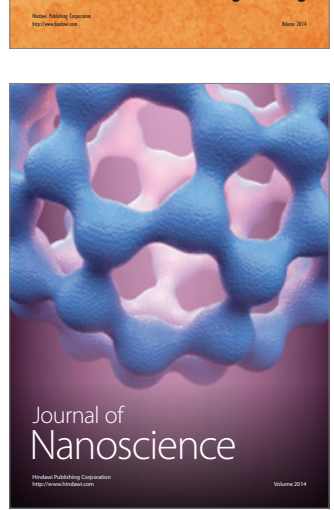
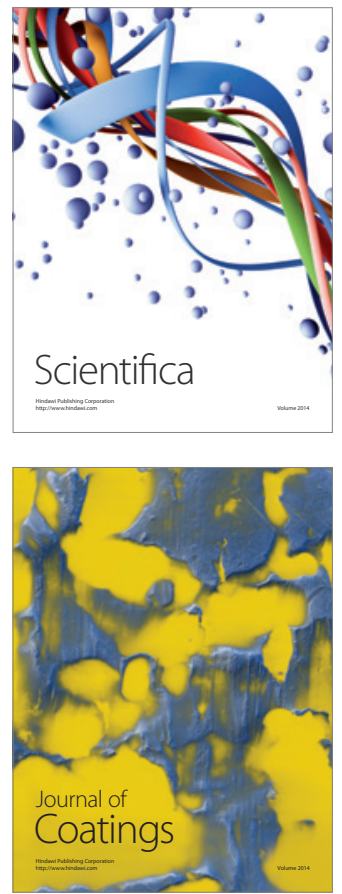
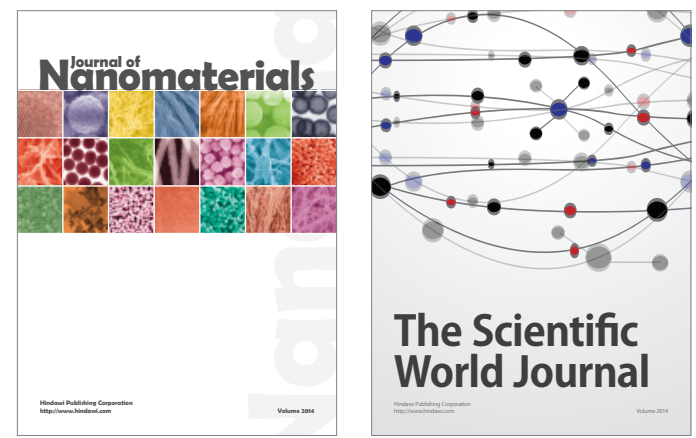

The Scientific World Journal
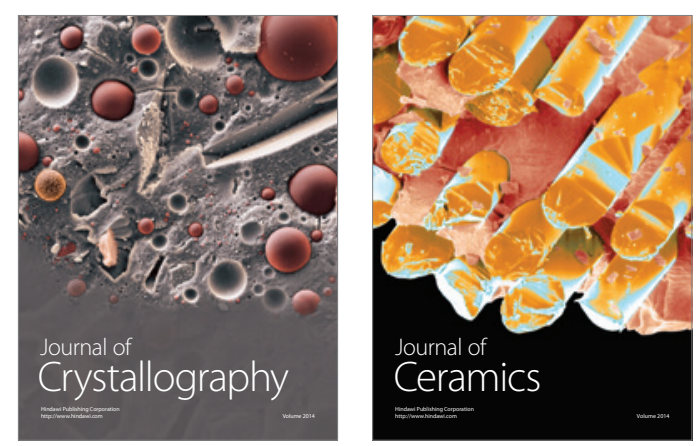
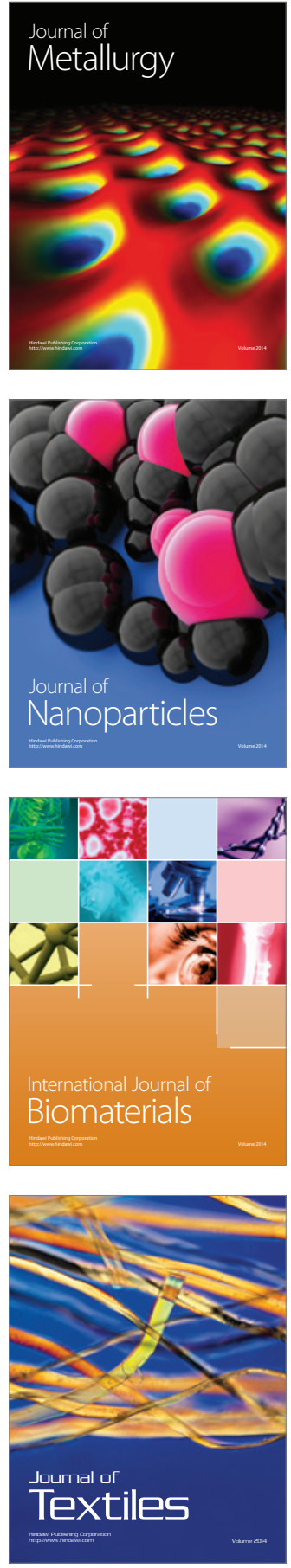